\title{
Abnormal Cell Responses and Role of TNF- $\alpha$ in Impaired Diabetic Wound Healing
}

\author{
Fanxing Xu, ${ }^{1,2}$ Chenying Zhang, ${ }^{2,3}$ and Dana T. Graves ${ }^{2}$ \\ ${ }^{1}$ School of Life Science and Biotechnology, Dalian University of Technology, Dalian 116024, China \\ ${ }^{2}$ Department of Periodontics, School of Dental Medicine, University of Pennsylvania, Philadelphia, \\ PA 19104, USA \\ ${ }^{3}$ Department of Preventive Dentistry, School and Hospital of Stomatology, Peking University, Beijing 100081, China \\ Correspondence should be addressed to Dana T. Graves; dtgraves@dental.upenn.edu
}

Received 25 October 2012; Accepted 17 December 2012

Academic Editor: Jorge Berlanga Acosta

Copyright (C) 2013 Fanxing Xu et al. This is an open access article distributed under the Creative Commons Attribution License, which permits unrestricted use, distribution, and reproduction in any medium, provided the original work is properly cited.

Impaired diabetic wound healing constitutes a major health problem. The impaired healing is caused by complex factors such as abnormal keratinocyte and fibroblast migration, proliferation, differentiation, and apoptosis, abnormal macrophage polarization, impaired recruitment of mesenchymal stem cells (MSCs) and endothelial progenitor cells (EPCs), and decreased vascularization. Diabetes-enhanced and prolonged expression of TNF- $\alpha$ also contributes to impaired healing. In this paper, we discuss the abnormal cell responses in diabetic wound healing and the contribution of TNF- $\alpha$.

\section{Introduction}

Diabetes mellitus is one of the most prevalent and costly chronic diseases in the United States [1]. Impaired wound healing and diabetic foot ulcers constitute a major health problem in patients with diabetes. Diabetic foot ulceration is estimated to occur in $15 \%$ of diabetic patients, often requires prolonged hospitalization for its management, and is a major cause of disease-associated amputations in the western world [2].

Wound healing is a complex process involving a number of interdependent and overlapping stages including hemostasis, inflammation, proliferation, vascularization, and production of matrix and remodeling [3]. Many types of cells are involved in each phase of wound healing including immune cells, endothelial cells, keratinocytes, and fibroblasts which undergo marked changes in gene expression and phenotype $[4,5]$. The delayed wound healing in diabetes is caused by complex factors such as diminished keratinocyte and fibroblast migration, proliferation, differentiation, apoptosis, and vascularization. Several of these cellular deficits have been linked to greater inflammation and proinflammatory cytokine production [6] (Figure 1).
Diabetic foot ulcers result from the simultaneous action of multiple contributing causes. A critical triad of neuropathy, minor foot trauma, and foot deformity is responsible for over $50 \%$ of diabetic foot ulcers [7]. Inflammation, immunodeficiency, peripheral neuropathy and ischemia from peripheral vascular disease, and subsequent infection are underlying factors that contribute to unhealed chronic wounds in diabetic foot ulcers [8].

One aspect of diabetic healing that has recently received considerable attention is the enhanced and prolonged expression of TNF- $\alpha$, a potent proinflammatory cytokine [9].This review focuses on factors that are affected by diabetesenhanced inflammation, particularly elevated or prolonged expression of TNF- $\alpha$.

\section{Cells Affected by Diabetes in Wound Healing}

The inflammatory stage of wound repair occurs shortly after tissue damage. After acute injury, platelets and neutrophils are released passively from disrupted blood vessels. The formation of a fibrin clot provides a temporary scaffold for infiltration of inflammatory cells. A large number of growth factors are important in stimulating and coordinating 


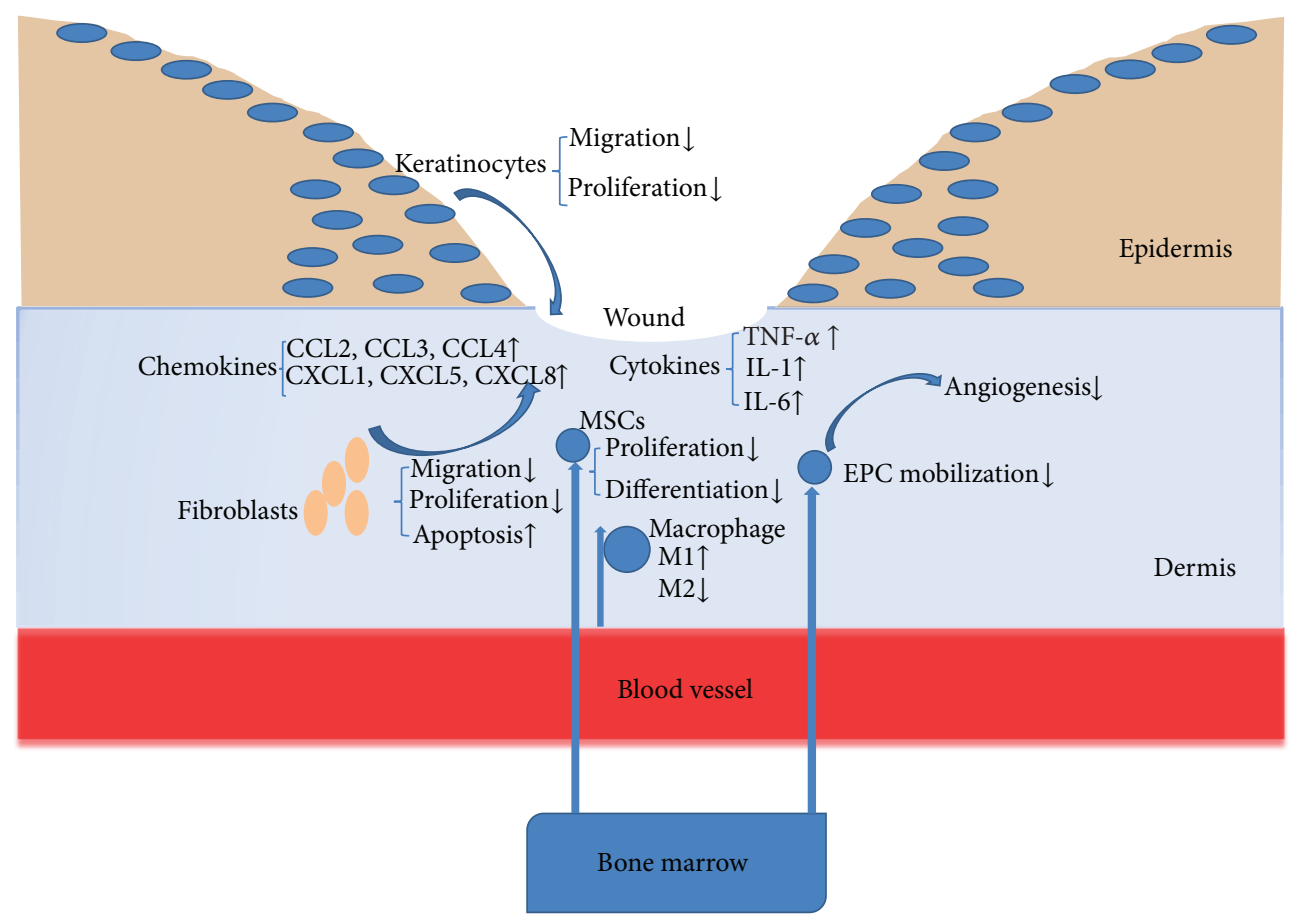

FIGURE 1: Mechanisms of impaired diabetic wound healing. The normal wound-healing process is initiated by the integration of multiple intercellular signals (cytokines and chemokines) released by keratinocytes, fibroblasts, endothelial cells, macrophages, platelets, etc. In diabetes, inflammatory cytokines and chemokines are elevated, such as TNF- $\alpha$, IL-1, IL-6, CCL2, CCL3, CCL4, CXCL1, CXCL5, and CXCL8. Cellular processes affected by diabetes include abnormal keratinocyte and fibroblast migration, proliferation, and enhanced apoptosis; abnormal macrophage polarization (increased proinflammatory M1 macrophages and decreased anti-inflammatory M2 macrophages); impaired recruitment of mesenchymal stem cells (MSCs) and endothelial progenitor cells (EPCs), and decreased vascularization.

cellular events that occur during normal wound healing [10]. Among them, cytokines and chemokines are especially noted because of their roles in promoting inflammation, angiogenesis, leukocyte recruitment, recruitment of stem cells, and epithelialization. Proinflammatory cytokines that are elevated shortly after wounding both in human wounds, and animal wound models include IL- $1 \alpha$, IL- $1 \beta$, IL- 6 , IL12 , and TNF- $\alpha[11,12]$. Some proinflammatory cytokines and chemokines are essential for normal skin wound-healing process. Delayed wound healing is observed in IL-6-deficient mice [13]. It has been shown that deletion of IL-1 receptor signaling impairs oral wound healing due to its importance in upregulating an antibacterial defense but has relatively little impact on dermal healing [14]. The lack of ICAM-1 in mice results in prolonged wound healing because of the decreased recruitment of macrophages and other leukocytes $[15,16]$.

The CXC chemokine family of chemotactic cytokines CXCL1, CXCL5, and CXCL8 is expressed in keratinocytes and upregulated in wounding by stimulation of proinflammatory cytokines such as IL- 1 and TNF- $\alpha$, bacterial products, and hypoxia [17]. The induced expression of chemokines stimulates recruitment of leukocytes and monocytes, neutrophils, and macrophages to the wound site to remove foreign material, bacteria, dead cells, and damaged matrix [3]. Chemokine CX3CL1 and its receptor CX3CR1 were both highly induced at wound sites mediating recruitment of bone marrow-derived monocytes/macrophages in a mouse model of excisional skin wound healing [18]. CXCR3 chemokine receptor and its ligands CXCL11, CXCL10, and CXCL4 are also crucial for dermal maturation. Disruption of CXCR3 signaling in mice results in delayed reepithelialization [19]. Chemokines also induce recruitment of stem cells to sites of injury and include epithelial stem cells from hair follicles or sweat glands, endothelial progenitor cells, and mesenchymal stem cells [20-22].

Impaired wound healing in diabetic patients is accompanied by decreased early inflammatory cell infiltration but increased numbers of neutrophils and macrophages in late stages. These changes in inflammatory cell recruitment occur in conjunction with alterations in chemokine and growth factor expression [23]. An increase in inflammatory cytokines is observed in wounds of type- 1 diabetic patients including CD40, IL- $1 \alpha$, IL-2, IL-4, IL-5, granulocyte-macrophage colony-stimulating factor (GM-CSF), CCL3, and CCL4 [24]. In diabetic models, increased levels of the proinflammatory cytokines such as TNF- $\alpha$ and IL- 6 and decreased levels of anti-inflammatory IL-10 are observed in diabetic wound tissue compared to nondiabetic healing wound $[25,26]$. This leads to sustained expression of chemokines CXCL2 and CCL2 that cause prolonged infiltration of leukocytes during impaired healing in diabetic mice [27].

2.1. Macrophages. Wound-site macrophages represent a key player that drives wound inflammation. Macrophages are 
important in clearance of dead cells and debris within the wound. Depletion of macrophages during the inflammatory phase results in significant delay of wound repair in a mouse model [28]. Diabetes is known to compromise macrophage function including phagocytosis activity [29]. Macrophages isolated from wounds of diabetic mice and diabetic patients showed significant impairment in efferocytosis, leading to a higher burden of apoptotic cells in wound tissue as well as increased proinflammatory cytokine expression [25].

High glucose levels stimulate macrophages to enhance the production of proinflammatory cytokines such as IL- $1 \beta$, IL-6, IL-12, IL-18, TNF- $\alpha$, and IFN- $\gamma$ both in vivo and in vitro [12]. Macrophages may polarize along two lines that have functional differences, proinflammatory macrophages (M1), and anti-inflammatory macrophages (M2), which can be further subdivided in M2a (after exposure to IL-4 or IL-13), M2b (immune complexes in combination with IL$1 \beta$ or LPS), and M2c (IL-10, TGF- $\beta$ or glucocorticoids) [30]. M1 macrophages are polarized by the stimulation of IFN- $\gamma$, GM-CSF and in the presence of bacterial products such as LPS [30]. M1 macrophages have a proinflammatory phenotype exhibiting increased phagocytic activity and secretion of proinflammatory cytokines that aid in the removal of pathogens and damaged tissues [31, 32]. M2 macrophages have a polar opposite phenotype exhibiting high levels of anti-inflammatory cytokines and fibrogenic and angiogenic factors that serve to resolve inflammation and promote wound healing $[30,32]$. Recently, an additional M2 subtype (M2d) which involves "switching" from an inflammatory M1 into an angiogenic M2 phenotype was discovered [33]. M2d macrophages express high levels of IL-10 and VEGF and low levels of TNF- $\alpha$ and IL-12 [33]. Macrophage polarization may play an important role in the pathogenesis of obesity-induced insulin resistance and type 2 diabetes mellitus [34]. Macrophages isolated from diabetic mice exhibit greater infiltration by inflammatory M1 macrophages and may contribute to impaired diabetic wound healing [35].

Wound macrophages in the early stage of repair are more M1-like when the generation of inflammatory signals is important while M2 macrophages predominate in later stages of repair in response to the need for new tissue formation [36]. In the normal wounds, the M1 macrophage phase is relatively short and the phase with M2 macrophages is longer [37]. M2 macrophages are a prominent source of TGF- $\beta$, which promotes many aspects of wound repair including chemotaxis, wound contraction, angiogenesis, reepithelialization, and connective tissue regeneration [5]. Diabetes may prolong the phase of M1 macrophage polarization. In addition infection in chronic wounds leads to prolonged M1 macrophage activation, which in turn can delay healing $[38,39]$.

2.2. Mesenchymal Stem Cells. Adult mesenchymal stem cells (MSCs) have the capacity for self-renewal and differentiating into a variety of mesenchymal cell lineages such as fibroblasts, osteoblasts, adipocytes, and chondrocytes. Increasing evidence shows that MSCs participate in the regeneration of skin in cutaneous wounds [40]. Hypoxia-inducible factor$1 \alpha$ (HIF- $1 \alpha)$ and chemokines such as CCL2 facilitate MSC mobilization into the peripheral blood and to sites of wound healing [41, 42]. In addition to forming fibroblasts and myofibroblasts, MSCs also enhance wound healing through the secretion of mediators such as VEGF- $\alpha$, IGF-1, EGF, keratinocyte growth factor, angiopoietin-1, stromal-derived factor-1, CCL3, CCL4, and erythropoietin [43, 44]. MSCs also play an important role in immunomodulation and are anti-inflammatory. MSCs inhibit the proliferation and activation of effector T cells, natural killer (NK) cells, dendritic cells (DCs), and macrophages by promoting the formation of anti-inflammatory regulatory $\mathrm{T}$ cells [45]. Thus there are multiple mechanisms through which MSCs can promote wound healing.

Diabetes has detrimental effects on MSCs. Bone marrowderived MSCs from diabetic rats have reduced proliferation and reduced myogenic differentiation [46]. The application of autologous MSCs improves healing of chronic diabetic foot ulcers [47]. Local application of MSCs to the wound sites improves wound healing in normal and diabetic mice, with increased reepithelialization, cellularity, and angiogenesis [43]. MSCs enhance diabetic wound healing by reducing inflammation, upregulating the expression of growth factors, and promoting the proliferation of fibroblasts and basal keratinocytes in diabetic rats [48].

2.3. Keratinocytes. Wound healing requires the transition of basal and suprabasal keratinocytes from a sedentary phenotype to a migratory and hyperproliferative phenotype. The reepithelialization process involves local keratinocytes at the wound edges and epithelial stem cells from hair follicles or sweat glands $[49,50]$. Keratinocytes are a major source of growth factors such as TGF- $\beta$, VEGF, EGF, KGF, and TGF$\alpha$ that stimulate fibrogenesis and angiogenesis in adjacent tissue $[4,51,52]$. Although there is no direct evidence that the proliferative activity of keratinocytes is affected in diabetes, migration is impaired $[53,54]$. Keratinocytes at the chronic ulcer edge from diabetic patients have a reduced expression of migration markers $[53,55]$. In vitro keratinocytes have reduced migration and proliferation capacities in highglucose conditions [56].

2.4. Fibroblasts and Myofibroblasts. Fibroblasts are the primary source of extracellular matrix proteins such as collagen and fibronectin [57]. In diabetic oral and dermal wounds fibroblasts have decreased migration, proliferation, and increased apoptosis [58-60]. The proliferation and migration of diabetic rat fibroblasts are suppressed when the cells are cultured in high-glucose containing media [60, 61]. Myofibroblasts are specialized fibroblasts that contribute to wound healing by producing extracellular matrix and by generating a contractile force to bring the edges of a wound together. The transition from fibroblasts to myofibroblasts is influenced by mechanical stress, endothelin-1, TGF- $\beta$, and cellular fibronectin (ED-A splice variant) $[62,63]$. During acute wound healing in nondiabetic mice, mRNA levels for both TGF- $\beta$ RI and TGF- $\beta$ RII in wound tissue are elevated 
[64]. TGF- $\beta$ receptor elevation is reduced in chronic diabetic ulcers [65]. Diabetics have reduced levels of TGF- $\beta$ and reduced formation of myofibroblasts which may contribute to impaired wound contraction [66].

2.5. Endothelial Cells. Angiogenesis is a complex cascade of cellular, humoral, and molecular events, which initiates at the binding of growth factors to their receptors on the endothelial cells of existing vessels, such as VEGF. The stimulated endothelial cells proliferate and migrate into the wounded tissue to form small tubular canals which then mature [3]. Impaired angiogenesis is considered a major contributing factor to nonhealing wounds. Woundinduced hypoxia stimulates vascular regeneration by activating hypoxia-inducible transcription factors (HIF-1 $\alpha$ ), which increase the production of angiogenic growth factors such as VEGF and expression of the chemokine receptor CXCR4 [67]. The number and function of endothelial progenitors are reduced in diabetes mellitus [68, 69]. The importance of angiogenesis in contributing to impaired diabetic healing is demonstrated by improvement when diabetic wounds are treated with endothelial progenitors or VEGF. Injection of CD 34+ endothelial cell progenitors to the wounds of diabetic mice accelerates vascularization and healing of diabetic mouse skin wounds [70]. Topical application of VEGF also improves diabetic wound healing by locally upregulating growth factors PDGF and FGF-2 and promoting angiogenesis [71].

2.6. MMPs/TIMPs Imbalance in Diabetes. The balance between matrix metalloproteinases (MMPs) and tissue inhibitors of metalloproteinases (TIMPs) is crucial for normal wound healing processes. A low MMP/TIMP ratio is a good predictor of successful wound-healing in diabetic foot ulcers [72]. Diabetes creates an unfavorable ratio. It increases the activity and expression of MMP-9, MMP-2, and MMP8 while reducing TIMP- $2[73,74]$. The abnormally elevated level of MMPs may impair cell migration and result in sustained inflammation with net increased tissue destruction. In the chronic diabetic foot lesions, local administration of protease inhibitors reduces the ratio of MMP/TIMP and improves wound healing [68].

\section{Role of TNF- $\alpha$ in Diabetic Wounds}

In normal wound healing the highest levels of TNF- $\alpha$ are seen from 12 to $24 \mathrm{~h}$ after wounding [75]. After the completion of the proliferative phase of wound healing, TNF- $\alpha$ returns to basal levels. During the early phase of wound repair, it is predominantly expressed in polymorphonuclear leukocytes, and later by macrophages. It is also expressed in the hyperproliferative epithelium at the wound edge. TNF- $\alpha$ contributes to the stimulation of fibroblasts and keratinocytes the expression of growth factors and upregulation of antimicrobial defenses [76]. TNF- $\alpha$ levels are elevated in diabetes in part through increased oxidative stress that promotes inflammation [77]. Other factors may contribute to this elevation including the downregulation of CD33 that inhibits cytokine production
[78]. TNF- $\alpha$ is found threefold higher in diabetic mouse wounds than wounds in normal mice [59] and threefold higher found in wound fluid from nonhealing venous leg ulcers than in healing ulcers [79]. Chronic gastric ulcers are also associated with increased TNF- $\alpha[80]$.

3.1. Cellular Events Affected by TNF- $\alpha$. In diabetic wound healing impaired fibroblast proliferation has been linked to increased levels of TNF- $\alpha$ [81]. Inhibiting TNF in vivo significantly increases the number of proliferating fibroblasts but it has a little effect on fibroblast proliferation in normoglycemic mice [59]. Apoptosis of fibroblasts in diabetic mice is significantly higher than in normoglycemic counterparts $[59,82]$, and apoptosis is high in skin biopsies from diabetic foot ulcers $[83,84]$. TNF stimulates apoptosis of fibroblasts, keratinocytes, and endothelial cells in vitro $[85,86]$. A causeand-effect relationship has been established between the treatment of TNF blocker and reduced apoptosis which was elevated in diabetic healing [59]. Diabetes also impairs the migration of fibroblasts and keratinocytes [55, 87]. High levels of TNF- $\alpha$ inhibit cell migration [88]. This may occur by increasing the level of Smad 7 [89] and inhibiting the activation of the Smad 2/3 [90] (Figure 2).

The neutralization of TNF in the diabetic wounds improves wound angiogenesis and closure. Blocking TNF reduces the overproduction of small noncoding RNAs such as miR-200b in the diabetic wounds, which improves the expression of globin transcription factor-binding protein 2 (GATA2) and vascular endothelial growth factor receptor 2 (VEGFR2), both of which promote angiogenesis [91].

The ability of cells at the wound site to respond to insulin is reduced in diabetic wounds. Insulin insensitivity occurs when the response to insulin is reduced. Long-term treatment of cells with TNF- $\alpha$ contributes to reduced insulin sensitivity [92]. Insulin receptor expression in proliferating keratinocytes at the wound margins and in granulation tissue is reduced in diabetic mice but enhanced with anti-TNF- $\alpha$ antibody treatment [93]. The effect of neutralization of TNF$\alpha$ on insulin sensitivity may be involved in inhibiting the effects of TNF- $\alpha$ on the downregulation of GLUT4 genes that are required for normal insulin action, the downregulation of PPAR $\gamma$ which is an important insulin-sensitizing nuclear receptor, and the upregulation of Ser phosphorylation of IRS1 that results in a net decrease in insulin receptor-mediated signaling [94]. Thus, an important component of impaired diabetic wound healing may be due to the reduced sensitivity of cells that participate in the wound healing process to insulin stimulation, which is mediated in part by high levels of TNF.

\subsection{Effect of TNF-Induced FOXO1 on Diabetic Wound Heal-} ing. Some of the negative effects of diabetes-enhanced TNF on wound healing may be due to the impact of the FOXO1 transcription factor [77, 95]. FOXO1 activity is increased in a number of different diabetic conditions and may be detrimental because it induces cell cycle arrest and apoptosis and increases the production of proinflammatory cytokines 


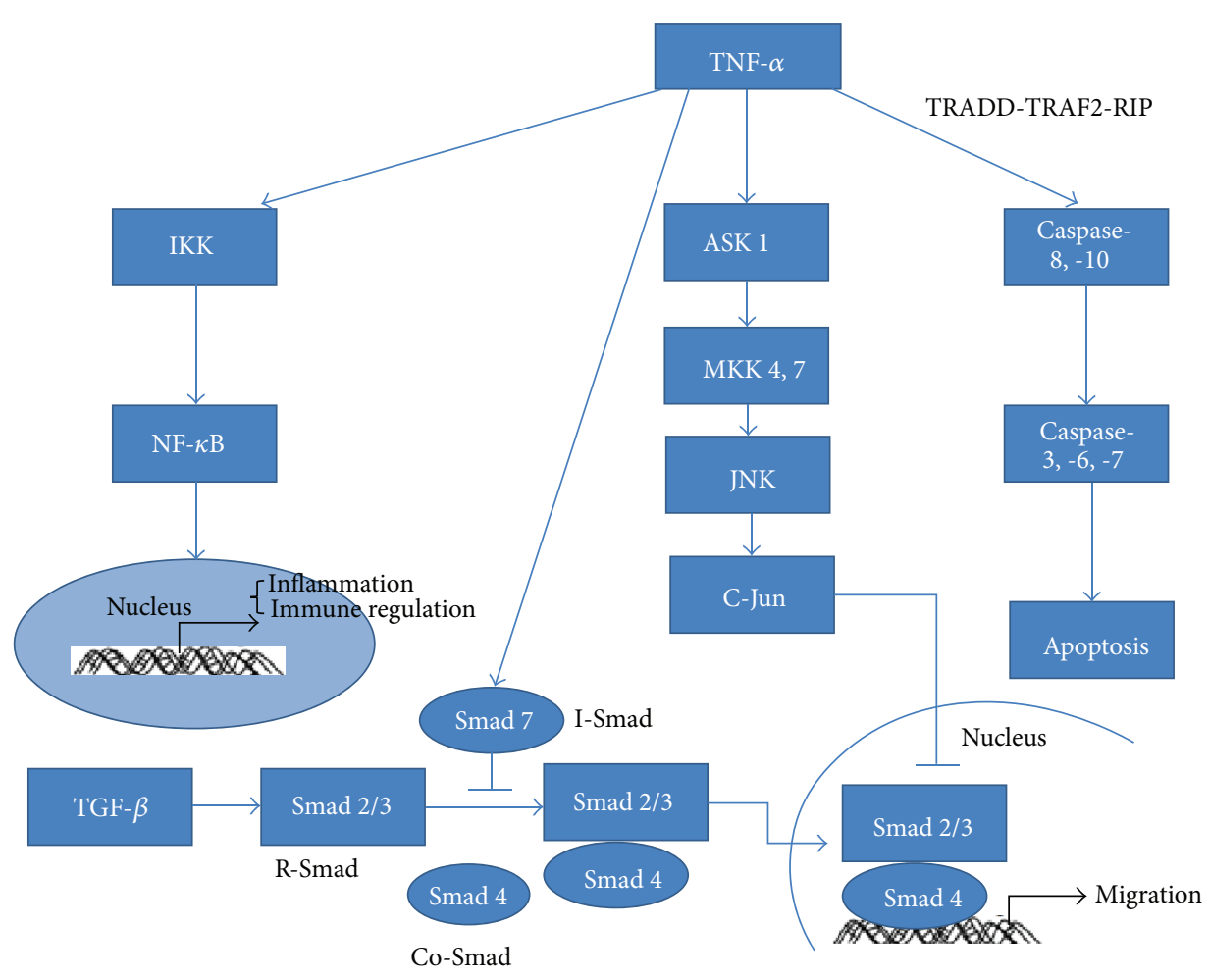

FIGURE 2: Model of TNF- $\alpha$ on regulation of inflammation, immue response, migration, and differentiation. TNF- $\alpha$ induces cell apoptosis via caspase pathway, and it negatively regulates cell migration by increasing the level of Smad 7 and inhibiting the activation of the Smad 2/3. TNF- $\alpha$ also induces NF- $\kappa$ B activation to enhance inflammatory responses.

[77]. TNF- $\alpha$-induced apoptosis of endothelial cells and pericytes is FOXO1 dependent in vivo and in vitro $[96,97]$. In vivo, FOXO1 DNA activity is increased twofold in diabetic wounds, and the increase is driven by diabetes-enhanced TNF levels [59]. FOXO1 activity is also increased in vivo in fracture healing and linked to greater inflammation $[98,99]$. In normal wound healing FOXO1 may play a positive role in endothelial migration and tube formation [95].

3.3. Advanced Glycation Endproducts. AGEs are proteins or lipids that become glycated after exposure to sugars. Enhanced formation and accumulation of advanced glycation end-products (AGEs) and receptors for AGEs have been reported to occur in diabetes mellitus [100-102]. The activation of one of the AGE receptors, (receptor for AGEs), RAGE causes the upregulation of the transcription factor nuclear factor-kappa B (NF-kappa B) and its target genes such as intercellular adhesion molecule-1 (ICAM-1), VEGF, IL$1 \alpha$, IL-6, and TNF- $\alpha$. Mice fed with high levels of AGE display impaired wound closure [103]. Blockade of RAGE restores effective wound healing in diabetic mice by accelerating reepithelialization and angiogenesis, limiting inflammatory cell infiltration, and reducing the expression of TNF- $\alpha$, IL6 , MMP-2, -3, and -9 [100]. AGEs cause the production of reactive oxygen species at least in part, through the activation of NADPH oxidase [77, 104]. In mononuclear phagocytes, AGEs increases the generation of cytokines such as TNF- $\alpha$,
IL-1, and IL-6 and enhanced the production of $\mathrm{O}^{2-}[101,105$, 106].

\section{Conclusion}

The impaired diabetic wound healing and diabetic ulcer impair the quality of life of millions of people and burden the healthcare systems globally. The etiological factors involve a high level of TNF- $\alpha$, which inhibits angiogenesis and cell proliferation and migration in diabetic wounds and increases apoptosis levels. TNF inhibition attenuates the impact of diabetes-enhanced TNF- $\alpha$, which offers potentially new therapeutic avenue for treatment of abnormally diabetic wounds healing.

\section{Authors' Contribution}

F. Xu and C. Zhang contributed equally to this work.

\section{Acknowledgments}

The authors would like to thank Sunitha Batchu for the help in preparing this paper. This study was supported by NIDCR Grant DE019108. 


\section{References}

[1] K. M. V. Narayan, J. P. Boyle, T. J. Thompson, S. W. Sorensen, and D. F. Williamson, "Lifetime risk for diabetes mellitus in the United States," The Journal of the American Medical Association, vol. 290, no. 14, pp. 1884-1890, 2003.

[2] American Diabetes Association, "Economic costs of diabetes in the U.S. in 2007," Diabetes Care, vol. 31, no. 3, pp. 596-615, 2008.

[3] J. M. Reinke and H. Sorg, "Wound repair and regeneration," European Surgical Research, vol. 49, no. 1, pp. 35-43, 2012.

[4] A. J. Singer and R. A. F. Clark, "Cutaneous wound healing," The New England Journal of Medicine, vol. 341, no. 10, pp. 738-746, 1999.

[5] M. Valluru, C. A. Staton, M. W. Reed et al., "Transforming growth factor- $\beta$ and endoglin signaling orchestrate wound healing," Frontiers in Physiology, vol. 2, article 89, 2011.

[6] R. Blakytny and E. Jude, "The molecular biology of chronic wounds and delayed healing in diabetes," Diabetic Medicine, vol. 23, no. 6, pp. 594-608, 2006.

[7] P. Leung, "Diabetic foot ulcers-a comprehensive review," The Surgeon, vol. 5, no. 4, pp. 219-231, 2007.

[8] R. G. Sibbald and K. Y. Woo, "The biology of chronic foot ulcers in persons with diabetes," Diabetes/Metabolism Research and Reviews, vol. 24, no. 1, pp. S25-S30, 2008.

[9] L. E. Tellechea A, A. Veves, and E. Carvalho, "Inflammatory and angiogenic abnormalities in diabetic wound healing: role of neuropeptides and therapeutic perspectives," The Open Circulation and Vascular Journal, vol. 3, pp. 43-55, 2010.

[10] G. C. Gurtner, S. Werner, Y. Barrandon, and M. T. Longaker, "Wound repair and regeneration," Nature, vol. 453, no. 7193, pp. 314-321, 2008.

[11] S. Barrientos, O. Stojadinovic, M. S. Golinko, H. Brem, and M. Tomic-Canic, "Growth factors and cytokines in wound healing," Wound Repair and Regeneration, vol. 16, no. 5, pp. 585-601, 2008

[12] Y. Wen, J. Gu, S. L. Li, M. A. Reddy, R. Natarajan, and J. L. Nadler, "Elevated glucose and diabetes promote interleukin-12 cytokine gene expression in mouse macrophages," Endocrinology, vol. 147, no. 5, pp. 2518-2525, 2006.

[13] Z. Q. Lin, T. Kondo, Y. Ishida, T. Takayasu, and N. Mukaida, "Essential involvement of IL-6 in the skin wound-healing process as evidenced by delayed wound healing in IL-6-deficient mice," Journal of Leukocyte Biology, vol. 73, no. 6, pp. 713-721, 2003.

[14] D. T. Graves, N. Nooh, T. Gillen et al., "IL-1 plays a critical role in oral, but not dermal, wound healing," Journal of Immunology, vol. 167, no. 9, pp. 5316-5320, 2001.

[15] T. Nagaoka, Y. Kaburagi, Y. Hamaguchi et al., "Delayed wound healing in the absence of intercellular adhesion molecule- 1 or L-selectin expression," The American Journal of Pathology, vol. 157, no. 1, pp. 237-247, 2000.

[16] T. Yukami, M. Hasegawa, Y. Matsushita et al., "Endothelial selectins regulate skin wound healing in cooperation with Lselectin and ICAM-1," Journal of Leukocyte Biology, vol. 82, no. 3, pp. 519-531, 2007.

[17] S. Zaja-Milatovic and A. Richmond, "CXC chemokines and their receptors: a case for a significant biological role in cutaneous wound healing," Histology and Histopathology, vol. 23, no. 11, pp. 1399-1407, 2008.

[18] Y. Ishida, J. L. Gao, and P. M. Murphy, "Chemokine receptor CX3CR1 mediates skin wound healing by promoting macrophage and fibroblast accumulation and function," Journal of Immunology, vol. 180, no. 1, pp. 569-579, 2008.

[19] C. C. Yates, D. Whaley, P. Kulasekeran et al., "Delayed and deficient dermal maturation in mice lacking the CXCR3 ELRnegative CXC chemokine receptor," The American Journal of Pathology, vol. 171, no. 2, pp. 484-495, 2007.

[20] R. E. Newman, D. Yoo, M. A. LeRoux, and A. DanilkovitchMiagkova, "Treatment of inflammatory diseases with mesenchymal stem cells," Inflammation and Allergy-Drug Targets, vol. 8, no. 2, pp. 110-123, 2009.

[21] E. N. Arwert, E. Hoste, and F. M. Watt, "Epithelial stem cells, wound healing and cancer," Nature Reviews Cancer, vol. 12, no. 3, pp. 170-180, 2012.

[22] P. J. Critser and M. C. Yoder, "Endothelial colony-forming cell role in neoangiogenesis and tissue repair," Current Opinion in Organ Transplantation, vol. 15, no. 1, pp. 68-72, 2010.

[23] O. Ochoa, F. M. Torres, and P. K. Shireman, "Chemokines and diabetic wound healing," Vascular, vol. 15, no. 6, pp. 350-355, 2007.

[24] A. Chatzigeorgiou, V. Harokopos, C. Mylona-Karagianni, E. Tsouvalas, V. Aidinis, and E. Kamper, "The pattern of inflammatory/anti-inflammatory cytokines and chemokines in type 1 diabetic patients over time," Annals of Medicine, vol. 42, no. 6, pp. 426-438, 2010.

[25] S. Khanna, S. Biswas, Y. Shang et al., "Macrophage dysfunction impairs resolution of inflammation in the wounds of diabetic mice," PLoS ONE, vol. 5, no. 3, Article ID e9539, 2010.

[26] B. C. Nwomeh, D. R. Yager, and I. K. Cohen, "Physiology of the chronic wound," Clinics in Plastic Surgery, vol. 25, no. 3, pp. 341-356, 1998.

[27] C. Wetzler, H. Kampfer, B. Stallmeyer, J. Pfeilschifter, and S. Frank, "Large and sustained induction of chemokines during impaired wound healing in the genetically diabetic mouse: prolonged persistence of neutrophils and macrophages during the late phase of repair," Journal of Investigative Dermatology, vol. 115, no. 2, pp. 245-253, 2000.

[28] T. Lucas, A. Waisman, R. Ranjan et al., "Differential roles of macrophages in diverse phases of skin repair," Journal of Immunology, vol. 184, no. 7, pp. 3964-3977, 2010.

[29] K. Maruyama, J. Asai, M. Ii, T. Thorne, D. W. Losordo, and P. A. D'Amore, "Decreased macrophage number and activation lead to reduced lymphatic vessel formation and contribute to impaired diabetic wound healing," The American Journal of Pathology, vol. 170, no. 4, pp. 1178-1191, 2007.

[30] F. O. Martinez, A. Sica, A. Mantovani, and M. Locati, "Macrophage activation and polarization," Frontiers in Bioscience, vol. 13, no. 2, pp. 453-461, 2008.

[31] M. Benoit, B. Desnues, and J. L. Mege, "Macrophage polarization in bacterial infections," Journal of Immunology, vol. 181, no. 6, pp. 3733-3739, 2008.

[32] X. Zhang and D. M. Mosser, "Macrophage activation by endogenous danger signals," Journal of Pathology, vol. 214, no. 2, pp. 161-178, 2008.

[33] S. Grinberg, G. Hasko, D. Wu, and S. J. Leibovich, "Suppression of PLC $\beta 2$ by endotoxin plays a role in the adenosine A $2 \mathrm{~A}$ receptor-mediated switch of macrophages from an inflammatory to an angiogenic phenotype," The American Journal of Pathology, vol. 175, no. 6, pp. 2439-2453, 2009.

[34] J. I. Odegaard and A. Chawla, "Mechanisms of macrophage activation in obesity-induced insulin resistance," Nature Clinical Practice Endocrinology and Metabolism, vol. 4, no. 11, pp. 619-626, 2008. 
[35] J. E. Kanter, F. Kramer, S. Barnhart et al., "Diabetes promotes an inflammatory macrophage phenotype and atherosclerosis through acyl-CoA synthetase 1," Proceedings of the National Academy of Sciences of the United States of America, vol. 109, no. 12, pp. E715-E724, 2012.

[36] J. M. Daley, S. K. Brancato, A. A. Thomay, J. S. Reichner, and J. E. Albina, "The phenotype of murine wound macrophages," Journal of Leukocyte Biology, vol. 87, no. 1, pp. 59-67, 2010.

[37] B. M. Delavary, W. M. van der Veer, M. van Egmond, F. B. Niessen, and R. H. J. Beelen, "Macrophages in skin injury and repair," Immunobiology, vol. 216, no. 7, pp. 753-762, 2011.

[38] J. L. Mège, V. Mehraj, and C. Capo, "Macrophage polarization and bacterial infections," Current Opinion in Infectious Diseases, vol. 24, no. 3, pp. 230-234, 2011.

[39] T. J. Koh and L. A. DiPietro, "Inflammation and wound healing: the role of the macrophage," Expert Reviews in Molecular Medicine, vol. 13, article e23, 2011.

[40] X. Fu and H. Li, "Mesenchymal stem cells and skin wound repair and regeneration: possibilities and questions," Cell and Tissue Research, vol. 335, no. 2, pp. 317-321, 2009.

[41] L. Liu, Q. Yu, J. Lin et al., "Hypoxia-inducible factor- $1 \alpha$ is essential for hypoxia-induced mesenchymal stem cell mobilization into the peripheral blood," Stem Cells and Development, vol. 20, no. 11, pp. 1961-1971, 2011.

[42] M. Sasaki, R. Abe, Y. Fujita, S. Ando, D. Inokuma, and H. Shimizu, "Mesenchymal stem cells are recruited into wounded skin and contribute to wound repair by transdifferentiation into multiple skin cell type," Journal of Immunology, vol. 180, no. 4, pp. 2581-2587, 2008.

[43] Y. Wu, L. Chen, P. G. Scott, and E. E. Tredget, "Mesenchymal stem cells enhance wound healing through differentiation and angiogenesis," Stem Cells, vol. 25, no. 10, pp. 2648-2659, 2007.

[44] L. Chen, E. E. Tredget, P. Y. G. Wu, Y. Wu, and Y. $\mathrm{Wu}$, "Paracrine factors of mesenchymal stem cells recruit macrophages and endothelial lineage cells and enhance wound healing," PLoS ONE, vol. 3, no. 4, Article ID e1886, 2008.

[45] N. G. Singer and A. I. Caplan, "Mesenchymal stem cells: mechanisms of inflammation," Annual Review of Pathology, vol. 6, pp. 457-478, 2011.

[46] P. Jin, X. Zhang, Y. Wu et al., "Streptozotocin-induced diabetic rat-derived bone marrow mesenchymal stem cells have impaired abilities in proliferation, paracrine, antiapoptosis, and myogenic differentiation," Transplantation Proceedings, vol. 42, no. 7, pp. 2745-2752, 2010.

[47] J. Vojtassak, L. Danisovic, M. Kubes et al., "Autologous biograft and mesenchymal stem cells in treatment of the diabetic foot," Neuro Endocrinology Letters, vol. 27, supplement 2, pp. 134-137, 2006.

[48] Y. R. Kuo, C. T. Wang, J. T. Cheng et al., "Bone marrow-derived mesenchymal stem cells enhanced diabetic wound healing through recruitment of tissue regeneration in a rat model of streptozotocin-induced diabetes," Plastic and Reconstructive Surgery, vol. 128, no. 4, pp. 872-880, 2011.

[49] C. Roh and S. Lyle, "Cutaneous stem cells and wound healing," Pediatric Research, vol. 59, no. 4, part 2, pp. 100R-103R, 2006.

[50] K. Lau, R. Paus, S. Tiede, P. Day, and A. Bayat, "Exploring the role of stem cells in cutaneous wound healing," Experimental Dermatology, vol. 18, no. 11, pp. 921-933, 2009.

[51] S. Werner and R. Grose, "Regulation of wound healing by growth factors and cytokines," Physiological Reviews, vol. 83, no. 3, pp. 835-870, 2003.
[52] P. Martin, "Wound healing-aiming for perfect skin regeneration," Science, vol. 276, no. 5309, pp. 75-81, 1997.

[53] H. Galkowska, W. L. Olszewski, U. Wojewodzka, J. Mijal, and E. Filipiuk, "Expression of apoptosis-and cell cycle-related proteins in epidermis of venous leg and diabetic foot ulcers," Surgery, vol. 134, no. 2, pp. 213-220, 2003.

[54] H. Galkowska, U. Wojewodzka, and W. L. Olszewski, "Chemokines, cytokines, and growth factors in keratinocytes and dermal endothelial cells in the margin of chronic diabetic foot ulcers," Wound Repair and Regeneration, vol. 14, no. 5, pp. 558-565, 2006.

[55] M. L. Usui, J. N. Mansbridge, W. G. Carter, M. Fujita, and J. E. Olerud, "Keratinocyte migration, proliferation, and differentiation in chronic ulcers from patients with diabetes and normal wounds," Journal of Histochemistry and Cytochemistry, vol. 56, no. 7, pp. 687-696, 2008.

[56] C. C. E. Lan, I. H. Liu, A. H. Fang, C. H. Wen, and C. S. Wu, "Hyperglycaemic conditions decrease cultured keratinocyte mobility: implications for impaired wound healing in patients with diabetes," British Journal of Dermatology, vol. 159, no. 5, pp. 1103-1115, 2008.

[57] S. Werner, T. Krieg, and H. Smola, "Keratinocyte-fibroblast interactions in wound healing," Journal of Investigative Dermatology, vol. 127, no. 5, pp. 998-1008, 2007.

[58] T. Desta, J. Li, T. Chino, and D. T. Graves, "Altered fibroblast proliferation and apoptosis in diabetic gingival wounds," Journal of Dental Research, vol. 89, no. 6, pp. 609-614, 2010.

[59] M. F. Siqueira, J. Li, L. Chehab et al., "Impaired wound healing in mouse models of diabetes is mediated by TNF$\alpha$ dysregulation and associated with enhanced activation of forkhead box O1 (FOXO1)," Diabetologia, vol. 53, no. 2, pp. 378-388, 2010.

[60] M. L. Lamers, M. E. S. Almeida, M. Vicente-Manzanares, A. F. Horwitz, and M. F. Santos, "High glucose-mediated oxidative stress impairs cell migration," PLoS ONE, vol. 6, no. 8, Article ID e22865, 2011.

[61] K. Hehenberger, A. Hansson, J. D. Heilborn, S. M. AbdelHalim, G. Ostensson, and K. Brismar, "Impaired proliferation and increased L-lactate production of dermal fibroblasts in the GK-rat, a spontaneous model of non-insulin dependent diabetes mellitus," Wound Repair and Regeneration, vol. 7, no. 1, pp. 65-71, 1999.

[62] G. Gabbiani, "The myofibroblast in wound healing and fibrocontractive diseases," Journal of Pathology, vol. 200, no. 4, pp. 500-503, 2003.

[63] P. Shephard, B. Hinz, S. Smola-Hess, J. J. Meister, T. Krieg, and H. Smola, "Dissecting the roles of endothelin, TGF- $\beta$ and GM-CSF on myofibroblast differentiation by keratinocytes," Thrombosis and Haemostasis, vol. 92, no. 2, pp. 262-274, 2004.

[64] S. Frank, M. Madlener, and S. Werner, "Transforming growth factors $\beta 1, \beta 2$, and $\beta 3$ and their receptors are differentially regulated during normal and impaired wound healing," The Journal of Biological Chemistry, vol. 271, no. 17, pp. 10188-10193, 1996.

[65] E. B. Jude, R. Blakytny, J. Bulmer, A. J. M. Boulton, and M. W. J. Ferguson, "Transforming growth factor-beta 1, 2, 3 and receptor type I and II in diabetic foot ulcers," Diabetic Medicine, vol. 19, no. 6, pp. 440-447, 2002.

[66] F. Al-Mulla, S. J. Leibovich, I. M. Francis et al., "Impaired TGF- $\beta$ signaling and a defect in resolution of inflammation contribute to delayed wound healing in a female rat model of type 2 diabetes," Molecular Biosystems, vol. 7, no. 11, pp. 3006-3020, 2011. 
[67] M. Detmar, L. F. Brown, B. Berse et al., "Hypoxia regulates the expression of vascular permeability factor/vascular endothelial growth factor (VPF/VEGF) and its receptors in human skin," Journal of Investigative Dermatology, vol. 108, no. 3, pp. 263-268, 1997.

[68] G. P. Fadini, M. Miorin, M. Facco et al., "Circulating endothelial progenitor cells are reduced in peripheral vascular complications of type 2 diabetes mellitus," Journal of the American College of Cardiology, vol. 45, no. 9, pp. 1449-1457, 2005.

[69] C. J. M. Loomans, E. J. P. de Koning, F. J. T. Staal et al., "Endothelial progenitor cell dysfunction: a novel concept in the pathogenesis of vascular complications of type 1 diabetes," Diabetes, vol. 53, no. 1, pp. 195-199, 2004.

[70] E. Sivan-Loukianova, O. A. Awad, V. Stepanovic, J. Bickenbach, and G. C. Schatteman, "CD34+ blood cells accelerate vascularization and healing of diabetic mouse skin wounds," Journal of Vascular Research, vol. 40, no. 4, pp. 368-377, 2003.

[71] R. D. Galiano, O. M. Tepper, C. R. Pelo et al., "Topical vascular endothelial growth factor accelerates diabetic wound healing through increased angiogenesis and by mobilizing and recruiting bone marrow-derived cells," The American Journal of Pathology, vol. 164, no. 6, pp. 1935-1947, 2004.

[72] M. Muller, C. Trocme, B. Lardy, F. Morel, S. Halimi, and P. Y. Benhamou, "Matrix metalloproteinases and diabetic foot ulcers: the ratio of MMP-1 to TIMP-1 is a predictor of wound healing," Diabetic Medicine, vol. 25, no. 4, pp. 419-426, 2008.

[73] S. Uemura, H. Matsushita, W. Li et al., "Diabetes mellitus enhances vascular matrix metalloproteinase activity role of oxidative stress," Circulation Research, vol. 88, no. 12, pp. 1291-1298, 2001.

[74] R. Lobmann, A. Ambrosch, G. Schultz, K. Waldmann, S. Schiweck, and H. Lehnert, "Expression of matrixmetalloproteinases and their inhibitors in the wounds of diabetic and non-diabetic patients," Diabetologia, vol. 45, no. 7 , pp. 1011-1016, 2002.

[75] Y. P. Han, T. L. Tuan, H. Wu, M. Hughes, and W. L. Garner, "TNF- $\alpha$ stimulates activation of pro-MMP2 in human skin through NF- $\kappa$ B mediated induction of MT1-MMP," Journal of Cell Science, vol. 114, no. 1, pp. 131-139, 2001.

[76] G. Hübner, M. Brauchle, H. Smola, M. Madlener, R. Fässler, and S. Werner, "Differential regulation of pro-inflammatory cytokines during wound healing in normal and glucocorticoidtreated mice," Cytokine, vol. 8, no. 7, pp. 548-556, 1996.

[77] B. Ponugoti, G. Dong, and D. T. Graves, "Role of forkhead transcription factors in diabetes-induced oxidative stress," Experimental Diabetes Research, vol. 2012, Article ID 939751, 7 pages, 2012.

[78] S. J. Orr, N. M. Morgan, J. Elliott et al., "CD33 responses are blocked by SOCS3 through accelerated proteasomal-mediated turnover," Blood, vol. 109, no. 3, pp. 1061-1068, 2007.

[79] H. J. Wallace and M. C. Stacey, "Levels of tumor necrosis factor$\alpha$ (TNF- $\alpha)$ and soluble TNF receptors in chronic venous leg ulcers-correlations to healing status," Journal of Investigative Dermatology, vol. 110, no. 3, pp. 292-296, 1998.

[80] I. A. Harsch, T. Brzozowski, K. Bazela et al., "Impaired gastric ulcer healing in diabetic rats: role of heat shock protein, growth factors, prostaglandins and proinflammatory cytokines," European Journal of Pharmacology, vol. 481, no. 2-3, pp. 249-260, 2003.

[81] G. C. Kaiser and D. B. Polk, "Tumor necrosis factor $\alpha$ regulates proliferation in a mouse intestinal cell line," Gastroenterology, vol. 112, no. 4, pp. 1231-1240, 1997.
[82] R. Liu, H. S. Bal, T. Desta, Y. Behl, and D. T. Graves, "Tumor necrosis factor- $\alpha$ mediates diabetes-enhanced apoptosis of matrix-producing cells and impairs diabetic healing," The American Journal of Pathology, vol. 168, no. 3, pp. 757-764, 2006.

[83] J. Hasnan, M. I. Yusof, T. D. Damitri, A. R. Faridah, A. S. Adenan, and T. H. Norbaini, "Relationship between apoptotic markers (Bax and bcl-2) and biochemical markers in type 2 diabetes mellitus," Singapore Medical Journal, vol. 51, no. 1, pp. 50-55, 2010.

[84] N. K. Rai, S. Bhan, M. Ansari, M. Kumar, V. K. Shukla, and K. Tripathi, "Effect of glycaemic control on apoptosis in diabetic wounds," Journal of wound care, vol. 14, no. 6, pp. 277-281, 2005.

[85] I. Petrache, L. E. Otterbein, J. Alam, G. W. Wiegand, and A. M. K. Choi, "Heme oxygenase- 1 inhibits TNF- $\alpha$-induced apoptosis in cultured fibroblasts," American Journal of Physiology, vol. 278, no. 2, pp. L312-L319, 2000.

[86] R. Ruckert, G. Lindner, S. Bulfone-Paus, and R. Paus, "Highdose proinflammatory cytokines induce apoptosis of hair bulb keratinocytes in vivo," British Journal of Dermatology, vol. 143, no. 5, pp. 1036-1039, 2000.

[87] H. Brem and M. Tomic-Canic, "Cellular and molecular basis of wound healing in diabetes," Journal of Clinical Investigation, vol. 117, no. 5, pp. 1219-1222, 2007.

[88] J. Corredor, F. Yan, C. C. Shen et al., “Tumor necrosis factor regulates intestinal epithelial cell migration by receptor-dependent mechanisms," American Journal of Physiology, vol. 284, no. 4, pp. C953-C961, 2003.

[89] M. Bitzer, G. von Gersdorff, D. Liang et al., "A mechanism of suppression of TGF- $\beta /$ SMAD signaling by NF- $\kappa \mathrm{B} /$ RelA," Genes and Development, vol. 14, no. 2, pp. 187-197, 2000.

[90] R. Arancibia, A. Oyarzun, D. Silva et al., "Tnf- $\alpha$ inhibits Tgf$\beta$-stimulated myofibroblastic differentiation and extracellular matrix production in human gingival fibroblasts," Journal of Periodontology. In press.

[91] Y. C. Chan, S. Roy, S. Khanna et al., "Downregulation of endothelial microRNA-200b supports cutaneous wound angiogenesis by desilencing GATA binding protein 2 and vascular endothelial growth factor receptor 2," Arteriosclerosis, Thrombosis, and Vascular Biology, vol. 32, no. 6, pp. 1372-1382, 2012.

[92] G. S. Hotamisligil, N. S. Shargill, and B. M. Spiegelman, "Adipose expression of tumor necrosis factor- $\alpha$ : direct role in obesity-linked insulin resistance," Science, vol. 259, no. 5091, pp. 87-91, 1993.

[93] I. Goren, E. Müller, J. Pfeilschifter, and S. Frank, "Severely impaired insulin signaling in chronic wounds of diabetic ob/ob mice: a potential role of tumor necrosis factor- $\alpha$, The American Journal of Pathology, vol. 168, no. 3, pp. 765-777, 2006.

[94] D. E. Moller, "Potential role of TNF- $\alpha$ in the pathogenesis of insulin resistance and type 2 diabetes," Trends in Endocrinology and Metabolism, vol. 11, no. 6, pp. 212-217, 2000.

[95] M. Potente, C. Urbich, K. I. Sasaki et al., "Involvement of Foxo transcription factors in angiogenesis and postnatal neovascularization," Journal of Clinical Investigation, vol. 115, no. 9, pp. 2382-2392, 2005.

[96] M. Alikhani, S. Roy, and D. T. Graves, "FOXO1 plays an essential role in apoptosis of retinal pericytes," Molecular Vision, vol. 16, pp. 408-415, 2010.

[97] Y. Behl, P. Krothapalli, T. Desta, S. Roy, and D. T. Graves, "FOXO1 plays an important role in enhanced microvascular 
cell apoptosis and microvascular cell loss in type 1 and type 2 diabetic rats," Diabetes, vol. 58, no. 4, pp. 917-925, 2009.

[98] J. Alblowi, R. A. Kayal, M. Siqueria et al., "High levels of tumor necrosis factor- $\alpha$ contribute to accelerated loss of cartilage in diabetic fracture healing," The American Journal of Pathology, vol. 175, no. 4, pp. 1574-1585, 2009.

[99] J. Brown, H. Wang, J. Suttles et al., "Mammalian target of rapamycin complex 2 (mTORC2) negatively regulates Tolllike receptor 4-mediated inflammatory response via FoxO1," The Journal of Biological Chemistry, vol. 286, no. 52, pp. 44295-44305, 2011.

[100] M. T. Goova, J. Li, T. Kislinger et al., "Blockade of receptor for advanced glycation end-products restores effective wound healing in diabetic mice," The American Journal of Pathology, vol. 159, no. 2, pp. 513-525, 2001.

[101] Y. Ding, A. Kantarci, H. Hasturk, P. C. Trackman, A. Malabanan, and T. E. Van Dyke, "Activation of RAGE induces elevated O2generation by mononuclear phagocytes in diabetes," Journal of Leukocyte Biology, vol. 81, no. 2, pp. 520-527, 2007.

[102] S. F. Yan, R. Ramasamy, and A. M. Schmidt, "The receptor for advanced glycation endproducts (RAGE) and cardiovascular disease," Expert Reviews in Molecular Medicine, vol. 11, article e9, 2009.

[103] M. Peppa, H. Brem, P. Ehrlich et al., "Adverse effects of dietary glycotoxins on wound healing in genetically diabetic mice," Diabetes, vol. 52, no. 11, pp. 2805-2813, 2003.

[104] A. Goldin, J. A. Beckman, A. M. Schmidt, and M. A. Creager, "Advanced glycation end products: sparking the development of diabetic vascular injury," Circulation, vol. 114, no. 6, pp. 597-605, 2006.

[105] M. Brownlee, A. Cerami, and H. Vlassara, "Advanced glycosylation end products in tissue and the biochemical basis of diabetic complications," The New England Journal of Medicine, vol. 318, no. 20, pp. 1315-1321, 1988.

[106] J. B. Acosta, D. G. del Barco, D. C. Vera et al., "The pro-inflammatory environment in recalcitrant diabetic foot wounds," International Wound Journal, vol. 5, no. 4, pp. 530-539, 2008. 


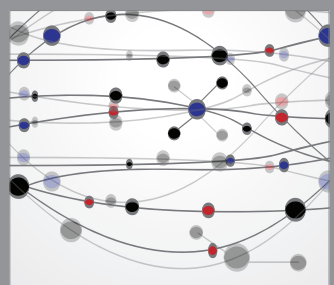

The Scientific World Journal
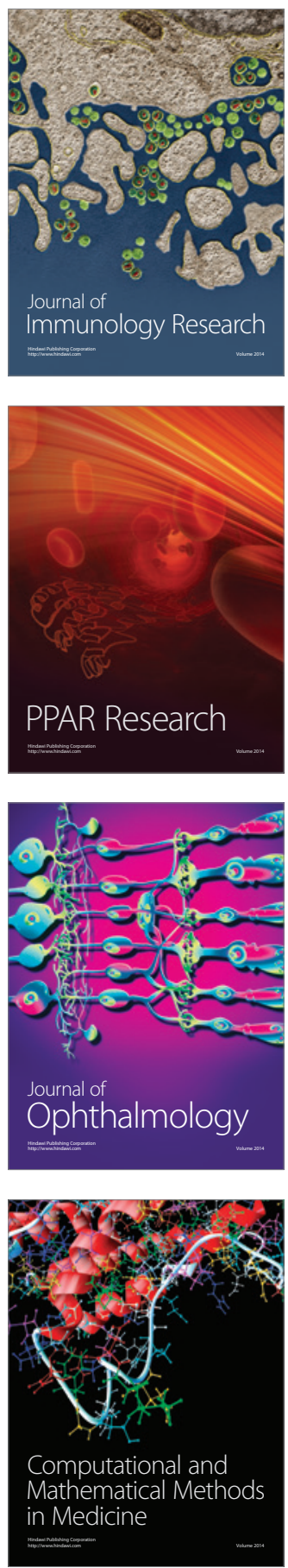

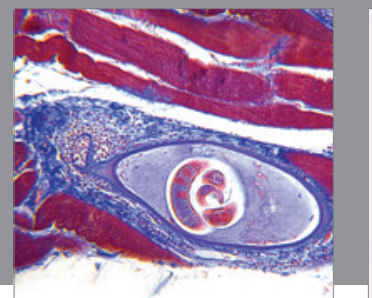

Gastroenterology

Research and Practice
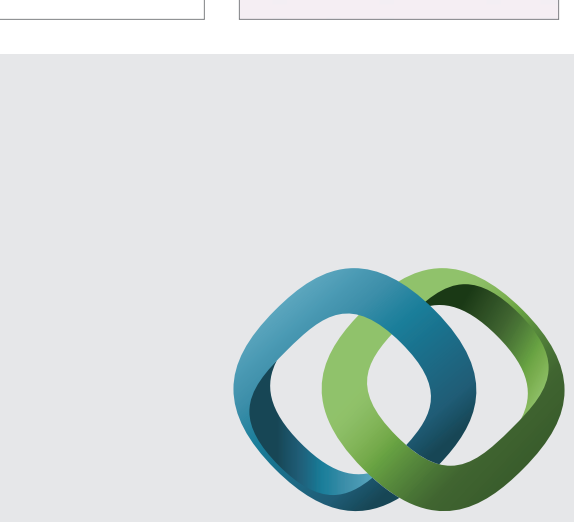

\section{Hindawi}

Submit your manuscripts at

http://www.hindawi.com
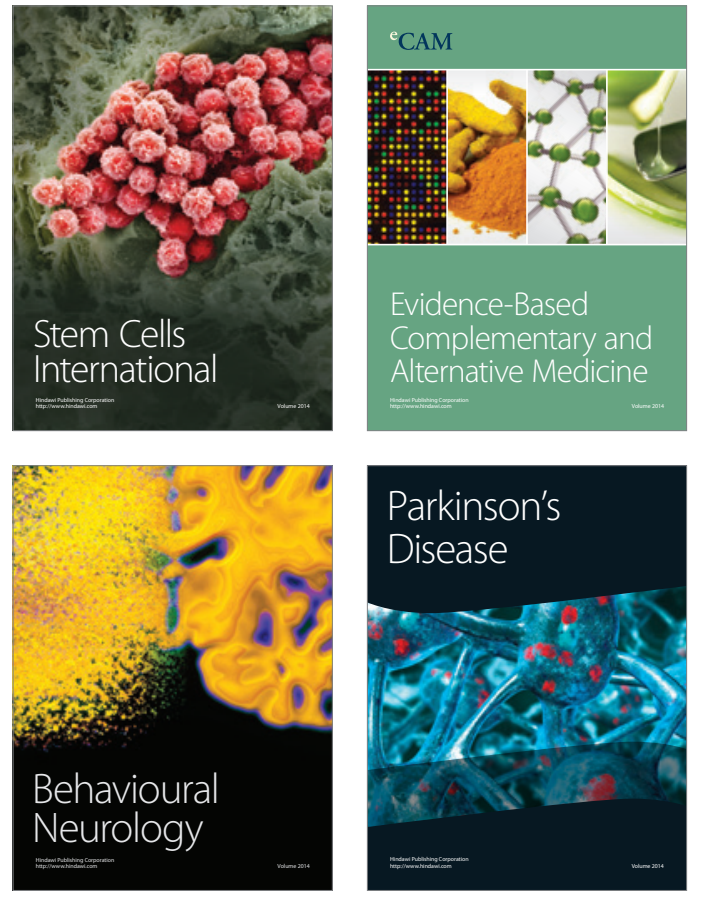
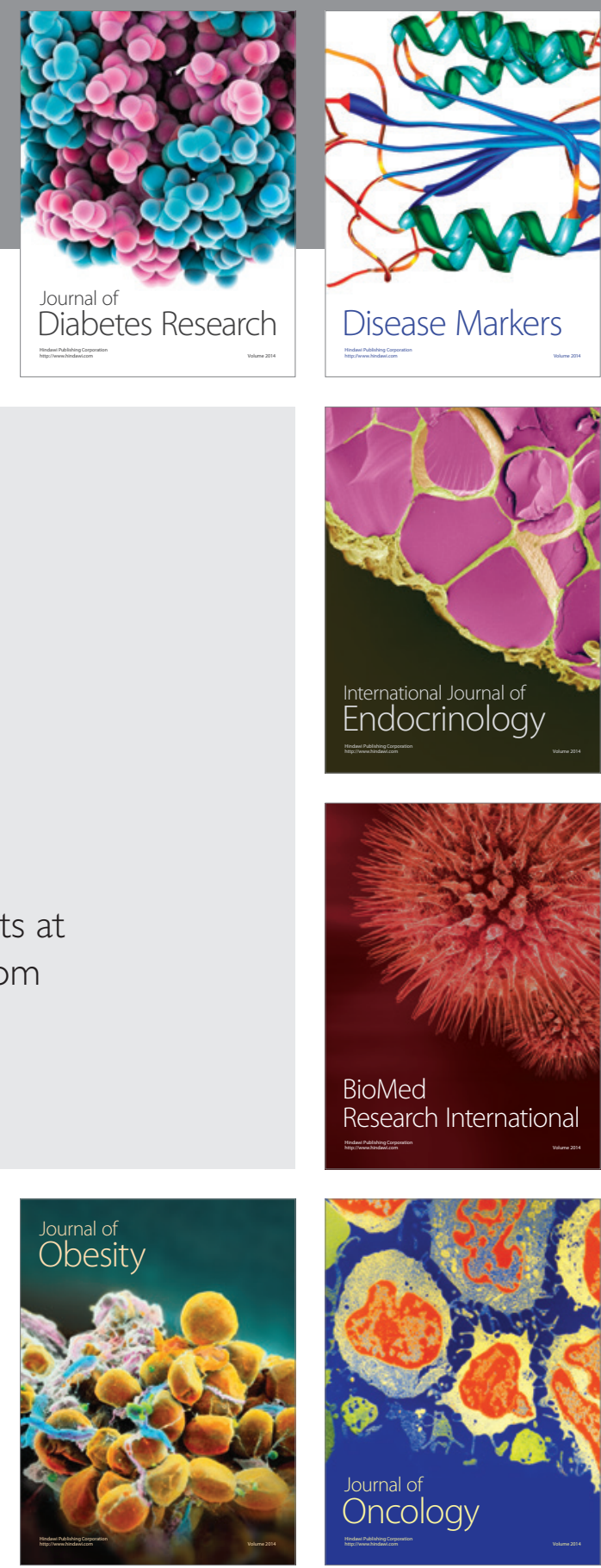

Disease Markers
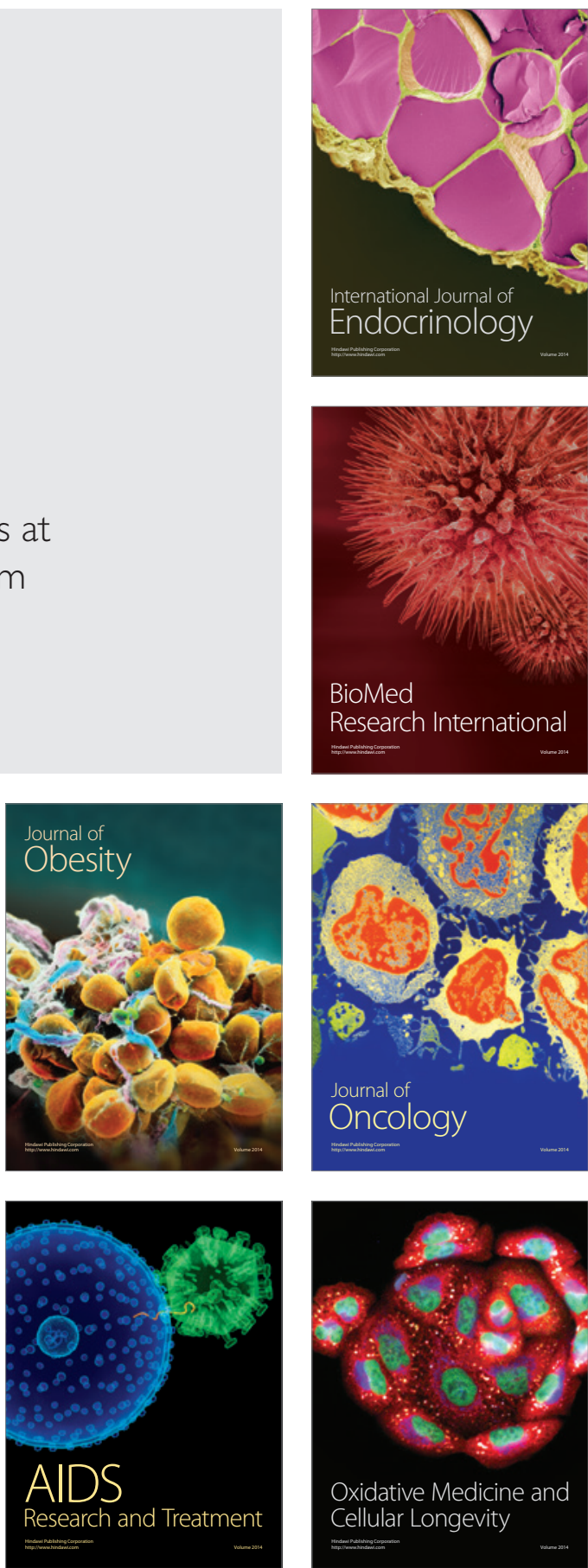